\title{
Twenty years' screening for cancer of the uterine cervix in Great Britain, 1964-84: further evidence for its ineffectiveness
}

\author{
M F G MURPHY,*1 2 M J CAMPBELL, ${ }^{3}$ AND P O GOLDBLATT 4
}

From the Office of Population Censuses and Surveys, ${ }^{1}$ London: Department of Community Medicine, ${ }^{2}$ University of Southampton; Department of Medical Statistics and Computing, ${ }^{3}$ University of Southampton; and Social Statistics Research Unit, ${ }^{4}$ City University London.

SUMMARY The effects of the screening programme for cancer of the uterine cervix in Great Britain are disputed, and the subject has been underexplored. Accordingly, we have related routinely available data on screening effort in Scotland, Wales, and the 14 English Health Regions to various incidence and mortality outcome measures, from 1967 to the present day. Although such an approach is imperfect, the results support the belief that the screening programme has been largely unsuccessful.

Carcinoma of the uterine cervix is a common disease worldwide and a major cause of mortality. ${ }^{12}$ In Great Britain, it is the eighth most commonly registered cancer in women and has claimed between two and three thousand lives per year since 1950 when mortality statistics showing it separately from other uterine cancer were first presented. In that time the trend in mortality has shown a slow, shallow decline. ${ }^{34}$ Nevertheless the disease attracts considerable interest from the point of view of primary and secondary prevention. Thus its main aetiology is thought to lie in the transmission of a carcinogen between the partners during heterosexual intercourse,,$^{56}$ and this may pose enormous problems for primary prevention. ${ }^{78}$ In contrast, for many years it has been regarded as a disease whose mortality might be reduced through screening, despite its inadequately understood natural history. ${ }^{9}$ In many countries, considerable resources have been devoted to this effort, ${ }^{2}$ and the results of several case-control studies have indicated that screening protects against the development of the malignancy. ${ }^{10-14}$ Yet in only a few places have time trends in the disease indicated that the anticipated reduction in incidence or mortality has been achieved. ${ }^{15}$

The effects of the screening programme in Great Britain are debated. ${ }^{16}$ In England and Wales, the use of modelling techniques has indicated that screening for the disease may have reduced the toll that might

* Present address: Department of Community Medicine and General Practice, Gibson Laboratories Building, Radcliffe Infirmary, Oxford OX2 6HE. otherwise have occurred. ${ }^{17}$ The little research using controls that has been carried out in Great Britain has been largely confined to Scotland where the small population makes interpretation difficult, and the comparison was simply of the burden of disease in a relatively well and relatively poorly screened population. ${ }^{18}$ Accordingly, we have adopted an approach similar to that previously used in Canada ${ }^{19}$ and the $\mathrm{USA}^{20}$ in which we evaluate the effectiveness of the screening programme by relating screening effort in the 14 English Health Regions, Wales, and Scotland to the subsequent incidence and mortality from the disease.

\section{Methods}

Routine data were obtained from the Department of Health and Social Security (DHSS) and the Office of Population Censuses and Surveys (OPCS) for the 14 English Health Regions and Wales, and from the General Register Office (GRO(S)) and Common Services Agency (CSA) for Scotland. For convenience we refer hereafter to these as 16 Regions of Great Britain. For 1967-84 annual returns of cervical smears examined in each of these 16 Regions are held by the DHSS and CSA (form SBH140 for England and Wales, ISD(D)I for Scotland). Data from the beginning of the screening programme in 1964 until 1966 are only available at the national level.

For the same Regions we obtained age-specific population and mortality data for carcinoma of the cervix for 1963-84 and age-specific registrations of 
carcinoma and carcinoma in situ of the cervix for 1963-82. Corresponding female all-cause mortality and all-cancer (except rodent ulcer) registration statistics were also obtained, as were approximate numbers of hysterectomy operations, wherein the cervix is completely removed, for the period 1967-83.

Two approaches were employed to investigate a linear relation between screening effort and subsequent disease. Firstly for each Region we calculated a linear regression over time of the crude smear rate for ages 15-64 and each of the 11 death and registration rates listed below. We then calculated the Spearman correlation coefficients between the slopes of the crude smear regressions and the slopes of the mortality and registration regressions for each of the six 10-year age groups between 15 and 74 and the broad age groupings $15-44,45-74,15-64,15-74$, and 75 and over.

Secondly, the mean Regional smear rates for populations aged 15-64 over three time periods were ranked, and Spearman's correlation coefficients with change, percentage change, and mean level of agestandardised mortality and registration were calculated. The indices used were the mortality ratio (SMR), proportional mortality ratio (SPMR), registration ratio (SRR), and proportional registration ratio (SPRR). These were all calculated using average Great Britain event rates in ten-year age groups between 15 and 64 as standard (1963-82 for registrations, 1963-84 for deaths). In addition, Regional SRRs and SPRRs were calculated using each Region's own average age-specific registration rates and proportions as standard.

Finally, we examined Regional variation in agestandardised hysterectomy operation ratios (SORs) for 1967-83 using the Great Britain average operation rates $1968-81$ at ages $25-74$ as standard. Using unpublished data from the Health Services Research Unit at Sheffield, we assessed the effect of including private operations on the Regional variation in SORs for the single year 1981 in England and Wales.

\section{Results}

Regional smear rates at ages 15-64 increased linearly 1964-84 except for a small inflection between 1974 and 1978 (range $R^{2}=0.78-0.99$ ). For age-specific mortality and registration data, however, straight line fits were poor except at a few ages (for example, 15-64), and there was no negative correlation between the Regional crude smear regressions and any of the 11 age-specific outcome regressions tested. We repeated this analysis excluding, first, Manchester/North Western and Liverpool/Mersey, and then excluding these two Regions and the four Thames Regions as well, because of probable complementary errors in the calculation of these Regions' smear rates. The only consistent strong negative correlation was for cervix cancer registrations at ages 15-24. With only ten Regions there was also a positive correlation of crude smear rates with registration rates of carcinoma in situ for several older age groups.

Table 1 shows the smear rates for populations aged 15-64 for the 16 Regions during 1967-73 and 1974-84. Different age-group based indices of screening effort were highly correlated, as was Regional screening between the two periods (Kendall's tau for 15-64 age group $=0.63, \mathrm{p}<0.001$ ) and within them from year to year, particularly during 1974-84. Only North West Thames and North Western Regions achieved an average population coverage of one smear every five years, and then only in 1974-84.

Table 2 shows Spearman's correlation coefficients between screening effort in the different periods (Regions ranked from 1 to 16 in descending order of smear rates), and the change and percentage change in the SMRs and SPMRs (Regions ranked from 1 to 16 in descending order of the size of the decrease in mortality), and the period value of these indices (Regions ranked 1 to 16 from lowest to highest levels of the indices). There are significant positive $\frac{\mathbb{Q}}{\mathrm{Q}}$ correlations of screening effort with mean level only, ie, high screening effort with low mortality. The same analyses for the SRR and SPRR indices, using Great Britain rates as standard, showed similar effects. For the SRR and SPRR indices, using Regional rates as standard, no significant results were obtained.

Table 3 shows the Regional variation in SORs. Although there is greater variation over time in the ranking than for screening effort, the SORs are correlated between 1967-73 and 1974-83 (Kendall's tau $=0.38, p<0.05$ ). The inclusion of private operations in 1981 alters the ranking but there is still a

Table 1 English Regions, Wales and Scotland: mean smear rates per 1000 women aged 15-64, 1967-84 (ranks are shown in parentheses with $1=$ highest rate)

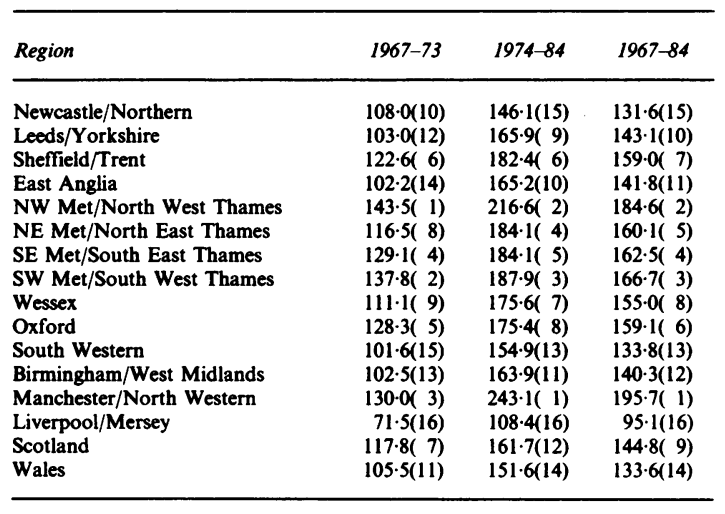


Twenty years' screening for cancer of the uterine cervix: further evidence for its ineffectiveness

Table 2 Spearman's correlation coefficients between Regional population screening and absolute change, percentage change and period levels of SMR and SPMR (age 15-64)

\begin{tabular}{|c|c|c|c|c|c|c|c|c|c|}
\hline $\begin{array}{l}\text { Screening } \\
\text { effort }\end{array}$ & $\begin{array}{c}\text { Change SMR } \\
1963 / 8-1968 / 73\end{array}$ & $\begin{array}{c}\% \text { Change SMR } \\
1963 / 8-1968 / 73\end{array}$ & $\begin{array}{c}S M R \\
1963-73\end{array}$ & $\begin{array}{c}\text { Change SMR } \\
1974 / 9-1979 / 84\end{array}$ & $\begin{array}{c}\% \text { Change SMR } \\
1974 / 9-1979 / 84\end{array}$ & $\begin{array}{c}S M R \\
1974-84\end{array}$ & $\begin{array}{c}\text { Change SMR } \\
1963 / 8-1979 / 84\end{array}$ & $\begin{array}{c}\% \text { Change SMR } \\
1963 / 8-1979 / 84\end{array}$ & $\begin{array}{c}S M R \\
1963-84\end{array}$ \\
\hline \multirow[t]{2}{*}{$\begin{array}{l}1967-73 \\
1974-84 \\
1967-84\end{array}$} & $\begin{array}{c}-0.19 \\
-\end{array}$ & $\begin{array}{c}-0.16 \\
-\end{array}$ & $\begin{array}{r}0.48 \\
-\end{array}$ & $\begin{array}{c}-0.23 \\
-0.19 \\
-\end{array}$ & $\begin{array}{c}-0.10 \\
-0.08 \\
-\end{array}$ & $\begin{array}{r}0.50 \\
0.49 \\
-\end{array}$ & $\begin{array}{l}-0.38 \\
-0.33 \\
-0.41\end{array}$ & $\begin{array}{l}-0.14 \\
-0.09 \\
-0.13\end{array}$ & $\begin{array}{l}0.50 \\
0.55^{*} \\
0.59^{*}\end{array}$ \\
\hline & $\begin{array}{l}\text { Change SPMR } \\
1963 / 8-1968 / 73\end{array}$ & $\begin{array}{c}\% \text { Change SPMR } \\
1963 / 8-1968 / 73\end{array}$ & $\begin{array}{c}\text { SPMR } \\
1963-73\end{array}$ & $\begin{array}{l}\text { Change SPMR } \\
1974 / 9-1979 / 84\end{array}$ & $\begin{array}{c}\text { \% Change SPMR } \\
1974 / 9-1979 / 84\end{array}$ & $\begin{array}{c}S P M R \\
1974-84\end{array}$ & $\begin{array}{l}\text { Change SPMR } \\
1963 / 8-1979 / 84\end{array}$ & $\begin{array}{c}\text { \% Change SPMR } \\
1963 / 8-1979 / 84\end{array}$ & $\begin{array}{c}S P M R \\
1963-84\end{array}$ \\
\hline $\begin{array}{l}1967-73 \\
1974-84 \\
1967-84\end{array}$ & $\begin{array}{c}-0.2 \\
- \\
-\end{array}$ & $\begin{array}{c}-0.16 \\
- \\
-\end{array}$ & $\begin{array}{c}0.56^{*} \\
- \\
-\end{array}$ & $\begin{array}{c}-0.13 \\
-0.09 \\
-\end{array}$ & $\begin{array}{c}-0.14 \\
-0.13 \\
-\end{array}$ & $\begin{array}{c}0.53^{*} \\
0.36 \\
-\end{array}$ & $\begin{array}{l}-0.15 \\
-0.25 \\
-0.25\end{array}$ & $\begin{array}{l}-0.06 \\
-0.15 \\
-0.14\end{array}$ & $\begin{array}{l}0.56^{*} \\
0.47 \\
0.57^{*}\end{array}$ \\
\hline
\end{tabular}

- not tested

- correlation coefficient significant at $5 \%$ level

Table 3 English Regions, Wales and Scotland: age-standardised hysterectomy ratios, 1967-83 (ranks are shown in parentheses from lowest to highest SOR)

\begin{tabular}{|c|c|c|c|c|c|}
\hline \multirow[t]{2}{*}{ Region } & \multirow[t]{2}{*}{$1967-83$} & \multirow[t]{2}{*}{$1974-83$} & \multirow[t]{2}{*}{$1967-83$} & \multicolumn{2}{|c|}{$\begin{array}{l}\text { England and Wales } \\
\text { only: } 1981 \text { SORs } \\
\text { adjusted by inclusion } \\
\text { of private operations }\end{array}$} \\
\hline & & & & $\begin{array}{l}\text { NHS } \\
\text { alone }\end{array}$ & $\begin{array}{c}\text { NHS + } \\
\text { private }\end{array}$ \\
\hline \multirow{16}{*}{$\begin{array}{l}\text { Newcastle/Northern } \\
\text { Leeds/Yorkshire } \\
\text { Sheffield/Trent } \\
\text { East Anglia } \\
\text { NW Met/NWT } \\
\text { NE Met/NET } \\
\text { SE Met/SET } \\
\text { SW Met/SWT } \\
\text { Wessex } \\
\text { Oxford } \\
\text { S Western } \\
\text { Birmingham/W Midlands } \\
\text { Manchester/N Western } \\
\text { Liverpool/Mersey } \\
\text { Scotland } \\
\text { Wales }\end{array}$} & \multirow{16}{*}{$\begin{array}{r}103 \cdot 8(8) \\
112 \cdot 1(14) \\
86 \cdot 8(4) \\
75 \cdot 6(2) \\
110 \cdot 2(13) \\
104 \cdot 4(9) \\
107 \cdot 6(11) \\
114 \cdot 9(15) \\
109 \cdot 4(12) \\
131 \cdot 3(16) \\
104 \cdot 8(10) \\
88 \cdot 0(5) \\
94 \cdot 3(6) \\
81 \cdot 5(3) \\
73 \cdot 6(1) \\
103 \cdot 0(7)\end{array}$} & \multirow{16}{*}{$\begin{array}{r}99 \cdot 8(7) \\
108 \cdot 7(13) \\
99 \cdot 9(8) \\
100 \cdot 5(9) \\
98 \cdot 8(4) \\
109 \cdot 0(14) \\
99 \cdot 0(6) \\
102 \cdot 1(10) \\
114 \cdot 2(16) \\
105 \cdot 7(12) \\
112 \cdot 2(15) \\
86 \cdot 6(1) \\
99 \cdot 0(5) \\
93 \cdot 4(3) \\
86 \cdot 7(2) \\
103 \cdot 2(11)\end{array}$} & \multirow{16}{*}{$\begin{array}{r}101 \cdot 5(7) \\
110 \cdot 0(14) \\
94 \cdot 4(5) \\
90 \cdot 6(4) \\
104 \cdot 1(10) \\
107 \cdot 2(11) \\
102 \cdot 5(8) \\
107 \cdot 8(12) \\
112 \cdot 5(15) \\
115 \cdot 3(16) \\
109 \cdot 1(13) \\
87 \cdot 2(2) \\
96 \cdot 9(6) \\
88 \cdot 8(3) \\
81 \cdot 3(1) \\
103 \cdot 1(9)\end{array}$} & $103 \cdot 2(9)$ & $109.9(6)$ \\
\hline & & & & $99.8(6)$ & $113.9(8)$ \\
\hline & & & & $103 \cdot 5(10)$ & $123.4(13)$ \\
\hline & & & & $108 \cdot 4(14)$ & $119 \cdot 6(11)$ \\
\hline & & & & $91 \cdot 2(3)$ & $102 \cdot 3(1)$ \\
\hline & & & & $102 \cdot 3(8)$ & $108 \cdot 6(5)$ \\
\hline & & & & $101.6(7)$ & $114 \cdot 1(9)$ \\
\hline & & & & $92.5(4)$ & $122 \cdot 3(12)$ \\
\hline & & & & $109 \cdot 8(15)$ & $119 \cdot 1(10)$ \\
\hline & & & & $106 \cdot 6(13)$ & $135 \cdot 3(15)$ \\
\hline & & & & $104 \cdot 3(11)$ & $124 \cdot 6(14)$ \\
\hline & & & & $90-8(2)$ & $103 \cdot 1(2)$ \\
\hline & & & & $105 \cdot 8(12)$ & $112.0(7)$ \\
\hline & & & & $89.0(1)$ & $107 \cdot 3(4)$ \\
\hline & & & & & \\
\hline & & & & $95 \cdot 7(5)$ & $105 \cdot 3(3)$ \\
\hline
\end{tabular}

For the period 1967-83, mean Great Britain NHS age-specific operation rates at ages 25-74 were used as standard.

For 1981, NHS age-specific operation rates were used as standard, since the age distribution of private operations was very similar to that of NHS operations at ages 15 and over.

high correlation between the NHS SOR and the all-operations SOR (Kendall's tau $=0.49, \mathrm{p}<0.05$ ).

\section{Discussion}

Our most consistent finding was an inverse relation between screening effort and age-adjusted mean levels of mortality in the different periods. However, the indices are highly correlated, and with such multiple testing the $5 \%$ level of significance is generous. ${ }^{21}$ The suggestion that the burden of cervix cancer would have been higher but for the existence of the screening programme is not supported by the absence of a relation between what is marked variation in screening effort and subsequent outcome. ${ }^{172223}$ This is demonstrated particularly in the lack of correlation between crude smear rates and outcome in the younger age groups where smears have been concentrated. Therefore either we have failed to detect a small, perhaps non-linear relation because our approach was insensitive, or there is little or no effect of the present screening programme in Great Britain.

Our data have several limitations. Smears performed do not equal women tested because of repetition if inadequate or to confirm positive findings, and some women have more tests than others. The extent to which Regional smear counts overstate the population tested ${ }^{24}$ is unknown. No 
choice for a crude smear rate denominator is ideal since Regional demographic structure varies, and the age profile of smears performed is largely unknown even at a national level, which precludes a cohort approach. ${ }^{25}$ We used the population aged 15-64 because smears are probably rare over age 65 , whereas women have been recruited to screening at increasingly young ages. ${ }^{26}$ Cross boundary flows between Regions affect where smear tests are both performed and processed. The resuiting imbalances are probably small, except between Manchester/ North Western and Liverpool/Mersey (R Yule, personal communication) and between the four London Regions, though here the distortions may cancel. Selective Regional migration is unlikely to be a problem ${ }^{27}$ since migration is maximal at younger ages (under 35 ) and undertaken by less than $8 \%$ of women over five years even then. Since all our data were assembled on the same basis, we ignored changes in Regional boundaries and, indeed, no discontinuities in the trends were apparent.

For outcome measures we prefer mortality, since cancer is among the better certified causes of death, and nearly all deaths are registered, ${ }^{28}$ though cervix cancer mortality data have been criticised. ${ }^{29}$ By the mid-1960s mortality ascribed to 'uterus NOS' was low throughout Great Britain, so mortality trends, if not absolute levels, are likely to be accurate over the period we considered, excepting 1981 when collection of statistics was disrupted by the Registrar's dispute.

Registration data, particularly for carcinoma in situ, are less satisfactory. Regional variation in the completeness of registration, and within Regions over time, disrupt the trends. ${ }^{30} 31$ Although we tried to allow for this using the SPRR as a measure of incidence, weight should not be placed on evidence from these registration data. Thus, we anticipated that screening effort would be related to the level of carcinoma in situ detected. ${ }^{22-24}$ but we found little evidence for this.

We did not adjust the Regional populations at risk for hysterectomies performed. This was shown to be important in the USA where operation rates are high. ${ }^{32}{ }^{33}$ Hysterectomy rates in Canada are similar, but little effect of this adjustment was found there. ${ }^{34}$ Operation rates are much lower in England and Wales, and there was only a small reduction in the population at risk up to 1975 , concentrated in the older age groups, ${ }^{35}$ though by 1984 the cumulative proportion of women in some age groups with their cervix removed may be substantial. ${ }^{16} 17$ For Scotland we showed that operation rates are lowest of all. However, we were primarily interested in Regional variation, which is not marked, even if private operations are included.

Our first approach looked for a simple relation between rates of change in the measures. Our second incorporated a different assessment of screening effort (proportion of women screened), the lag between this and the subsequent burden of disease, and adjusted for socioeconomic change and deficiencies in the outcome measures. In both cases the crucial assumption is of a linear relation. As Miller $e t a l^{34}$ have pointed out, this may not be warranted although it was suggested by their first study. ${ }^{19}$ Their final judgement was of an approximately linear relation until saturation screening was achieved among women prepared to be involved in the programme, after which only marginal reductions were observed. Our significant negative correlations of screening effort and mean levels of age-adjusted mortality are consistent with this idea.

The general evidence that adequately conducted programmes can be effective is persuasive, particularly for the Nordic countries. ${ }^{36} \mathrm{~A}$ population based (rather than high risk) strategy can succeed, ${ }^{37}$ but the relative contributions of opportunistic and dedicated screening are disputed. ${ }^{15} 38-41$ The deficiences of the screening programme in Great Britain are well rehearsed, ${ }^{4}$ but we support the continued availability of screening to younger women, not least because present cohort patterns suggest that the average age of women with the disease will decrease considerably. ${ }^{3}$ The effect of local computerised call and recall systems remains to be seen but, if they include personal smear history by age, they at least allow their own impact to be monitored accurately.

We thank Petra Clarke and Keith Naylor, of the DHSS, for the provision of data about cervical smears in England and Wales. Ian Kemp, Peter Trotter, Trevor Hill, David Salmond, Christine Rae, and Jenny Webb kindly provided the data from the GRO(S) and Information Services Division of the CSA for Scotland. Members of the Medical Statistics Division, OPCS, helped with the extraction of data and checked calculations. Lindsey Izzard and Lesley Brewster, of the Medical Statistics and Computing Group, Southampton, helped with data preparation and computing; Christina Perry, of the same department, typed the manuscript.

\section{References}

${ }^{1}$ Parkin D, Stjernsward J, Muir C. Estimates of the worldwide frequency of twelve major cancers. Bull $\mathrm{WHO}$ 1984; 62: 163-82.

${ }^{2}$ Lunt R. Worldwide early detection of cervical cancer. Obstet Gynaecol 1984; 63: 708-13.

${ }^{3}$ Beral V, Booth M. Predictions of cervical cancer incidence and mortality in England and Wales. Lancet 1986; i: 495.

${ }^{4}$ Cancer of the cervix: Death by Imcompetence. Lancet 1985; ii: $363-4$ 
${ }^{5}$ Buckley J, Harris R, Doll R, Vessey M, Williams P. Case-control study of the husbands of women with dysplasia or carcinoma of the cervix uteri. Lancet 1981; ii: 1010-5.

${ }^{6}$ Skegg D, Corwin P, Paul C, Doll R. Importance of the male factor in cancer of the cervix. Lancet 1982; ii: 581-3.

${ }^{7}$ Skinner E, Whitney J, Hartley C. Prevalence of typespecific antibody against Type 1 and Type 2 Herpes Simplex Virus in women with abnormal cervical cytology: Evidence towards prepubertal vaccination of seronegative female subjects. Arch Virol 1977; 54: 211-21.

${ }^{8}$ Singer A, McCance D. The wart virus and genital neoplasia; a casual or causal association. Br J Obstet Gynaecol 1985; 92: 1083-5.

${ }^{9}$ Cervical cancer screening: the Pap smear. Summary of an NIH consensus statement. Br Med J 1980; 281: 1264-6.

${ }^{10}$ Clarke E, Anderson T. Does screening by Pap smears help prevent cervical cancer? Lancet 1979; ii: 1-4.

${ }^{11}$ Raymond L, Obradovic M, Riotton G. A case-control study to estimate the detection of cancer of the cervix uteri by cytology. Rev Epidemiol Santé Publ. 1984; 32: 10-5.

12 Aristizabal N, Cuello C, Correa P, Collazos T, Haenszel W. The impact of vaginal cytology on cervical cancer risks in Cali, Colombia. Int J Cancer 1984; 34: 5-9.

${ }^{13}$ La Vecchia C, Franceschi S, Decarli A, Fasoli M, Gentile A, Torgnoni G. Pap smear and the risk of cervical neoplasia: quantitative estimates from a case-control study. Lancet 1984 ; ii: 779-82.

14 Macgregor J, Moss S, Parkin D, Day N. A case-control study of cervical cancer screening in north east Scotland. Br Med J 1985; 290: 1543-6.

${ }^{15}$ Pettersson F, Bjorkholm E, Naslund I. Evaluation of screening for cervical cancer in Sweden. Trends in incidence and mortality 1958-80. Int J Epidemiol 1985; 14: $521-7$

${ }^{16}$ Knox E. Cancer of the uterine cervix. In: Magnus K, ed. Trends in cancer incidence. Washington: Hemisphere 1982; 271-7.

${ }^{17}$ Parkin D, Nguyen-Dinh X, Day N. The impact of screening on the incidence of cervical cancer in England and Wales. Br J Obstet Gynaecol 1985; 92: 150-7.

18 Macgregor J, Teper S. Mortality from carcinoma of the cervix uteri in Britain. Lancet 1978; ii: 774-6.

${ }^{19}$ Miller A, Lindsay J, Hill G. Mortality from cancer of the uterus in Canada and its relationship to screening for cancer of the cervix. Int J Cancer 1976; 17: 602-12.

20 Cramer D. The role of cervical cytology in the declining morbidity and mortality of cervical cancer. Cancer 1974; 34: 2018-27.

21 Jones D, Rushton L. Simultaneous inference in epidemiological studies. Int J Epidemiol 1982; ii: 276-82.

22 Draper G, Cook G. Changing patterns of cervical cancer rates. $\mathrm{Br}$ Med J 1983; 287: 510-2.

${ }^{23}$ Cook G, Draper G. Trends in cervical cancer and carcinoma in situ in Great Britain. Br J Cancer 1984; 50: 367-75.
${ }^{24}$ Draper G. Screening for cervical cancer: revised policy. The recommendations of the DHSS Committee on Gynaecological cytology. Health Trends 1982; 14: 37-40.

25 Roberts A. Cervical cytology in England and Wales 1965-80. Health Trends 1982; 14: 41-3.

${ }^{26}$ DHSS. Unpublished data from the National Health Service Central Register at Southport, 1973-81.

${ }^{27}$ Fox AJ, Goldblatt PO. Longitudinal study: sociodemographic mortality differentials 1971-5. OPCS LS series no. 1. London: HMSO, 1982.

28 Heasman MA, Lipworth L. Accuracy of certification of cause of death. OPCS Studies on Medical and Population Subjects Number 20. London: HMSO, 1966.

${ }^{29}$ Duguid H, Duncan I, Currie J. Screening for cervical intraepithelial neoplasia in Dundee and Angus 1962-81 and its relation with invasive cervical cancer. Lancet 1985 ; ii: $1053-6$.

30 OPCS. Report of the Advisory Committee on Cancer Registration. London: HMSO 1980.

${ }^{31}$ Swerdlow AJ. Cancer registration in England and Wales: Some aspects relevant to interpretation of the data. $J$ Roy Stat Soc Series A (General) 1986; 149: 146-60.

32 Lyon J, Gardner J. The rising frequency of hysterectomy: its effects on uterine cancer rates. Am J Epidemiol 1977; 105: 439-43.

${ }^{33}$ Marrett L. Estimate of the true population at risk of uterine disease and an application to incidence data for cancer of the uterine corpus in Connecticut. $\mathrm{Am} \mathrm{J}$ Epidemiol 1980; 111: 373-8.

34 Miller A, Visentin T, Howe G. The effect of hysterectomies and screening on mortality from cancer of the uterus in Canada. Int J Cancer 1981; 27: 651-7.

35 Alderson M, Donnan S. Hysterectomy rates and their influence upon mortality from carcinoma of the cervix. $J$ Epidemiol Comm Hlth 1978; 32: 175-7.

${ }^{36}$ Hakama M. Trends in the incidence of cervical cancer in the Nordic countries. In: Magnus K, ed. Trends in cancer incidence. Washington: Hemisphere, 1982, 279-82.

${ }^{37}$ Hakama M, Chamberlain J, Day N, Miller A, Prorok P. Evaluation of screening programmes for gynaecological cancer. Br J Cancer 1985; 52: 669-73.

38 Parkin D, Moss S. An evaluation of screening policies for cervical cancer in England and Wales using a computer simulation model. J Epidemiol Community Health 1986; 40: 143-53.

${ }^{39}$ Screening strategies for cervical cancer. Lancet 1986; ii: 725-6.

${ }^{40}$ IARC Working Group on Evaluation of Cervical Cancer Screening Programmes. Screening for squamous cervical cancer: duration of low risk after negative results of cervical cytology and its implication for screening policies. Br Med J 1986; 293: 659-64.

${ }^{41}$ Laara E, Day N, Hakama M. Trends in mortality from cervical cancer in the Nordic countries: association with organised screening programmes. Lancet 1987; i: 1247-9. 